\title{
THE CORRELATION BETWEEN HUMIDITY, TEMPERATURE, AND NOISE WITH SLEEP QUALITY AT INTENSIVE CARE UNIT (ICU)
}

\author{
Sri Suparti ${ }^{1 *}$, Jebul Suroso ${ }^{2}$ \\ ${ }^{1,2}$ FIKES Universitas Muhammadiyah Purwokerto \\ Email*: srisuparti@ump.ac.id
}

\begin{abstract}
Introduction: Temperature, humidity, and noise are factors that affect sleep quality. The objective of the research is to determine the effect of humidity, temperature, and room noise on sleep quality of (Intensive Care Unit) ICU patients. Methods: A quantitative research with the cross-sectional approach, involving 84 patients taken by consecutive sampling, with the inclusion criteria of at least having already spent more than two days in ICU, having age between 20-70 years, and being conscious and cooperative. The patients were observed using observation sheets and The Richards-Campbell Sleep Questionnaire (RCSQ). A thermohygrometer and sound level meter for noise recording were used to measure the temperature and humidity. Simple linear regression was used to analyze the data. Results: It was found out that the average sleep quality of patients in the intensive room was 28.51, which categorized as poor sleep quality; the mean humidity in ICU was 56.98; the room temperature was 26.40, and the noise was 66.01. The noise level at the ICU significantly affected the patients' sleep quality ( $p$-value $=0.020<0.05)$, while temperature and humidity did not influence the patients' sleep quality. Conclusion: Most of the respondents had a poor quality of sleep. Controlling the conversation and activities among staff, using earplugs, and modifying the alarm can be done to reduce the noise at the ICU to enhance the quality of sleep of the patients.
\end{abstract}

Keywords: humidity; ICU; noise; sleep quality; temperature

\section{INTRODUCTION}

Patients who are treated in the ICU have unpleasant experiences, which include pain, fear, isolation, helplessness, anxiety, and sleep disorders. There were stress experience frequently reported by patients in the ICU, for instance bedridden (34.2\%) sleep problems, pain (34.0\%), general discomfort (31.7\%), daily pinprick (32.9\%), family concerns (33.6\%), fear of death and uncertainty in life (25.8\%), (Pieris et al., 2018). The prevalence of poor sleep quality in patients treated in the ICU in several countries, including Indonesia, are 50\%, (Bihari et al., 2012, Tembo, Parker, \& Higgins, 2013) 30\% (R., B., \& K., 2014), 73.1\%, (Rahmawan, 2013), 87.5\% (Afianti \& Mardhiyah, 2017), 47\% (Naik et al., 2018). Polysomnography recorded images from almost all patients treated in ICU experiencing sleep disorders seen from the stage of sleep, sleep efficiency, and arousal index (Ding, Redeker, Pisani, Yaggi, \& Knauert, 2017), (Wilcox et al., 2018).

Some of the factors associated with sleep quality of patients treated in the ICU are noise levels, discomfort, pain, nursing procedures, medical equipment, anxiety, light (Kaplow, 2016), (Dolan, Huh, Tiwari, Sproat, \& Camilleri-Brennan, 2016)(Ding et al., 2017) (Carrera-Hernández, Aizpitarte-Pejenaute, Zugazagoitia-Ciarrusta, \& Goñi-Viguria, 2018). A previous study conducted in Indonesia reported that poor sleep quality among patients in the ICU can occur due to sound pressure/noise level (53.3\%) lighting $(40.0 \%)$ and nursing interventions (43.3\%), (Hadi, 2017). Noise in the ICU at day time is approximately 60 decibels (dBA) then reaches its peak at $90 \mathrm{dBA}$ at noon, which exceed the normal value. Moreover, at night time the level of noise slightly decreases to $50 \mathrm{dBA}$ ( $\mathrm{He}$ et al, 2018). This finding is far higher than the standard level recommended by WHO, which is $35-40 \mathrm{dBA}$ during the day and $30-40 \mathrm{dBA}$ at night (Tainter et al., 2016).

Too cold and hot temperatures can cause sleep disorders of patients in the ICU. Furthermore, sleep deprivation is associated with immune and cardiovascular system dysfunction, impaired metabolism, impaired memory and cognition, and increased mortality (Şimşek, Solak Grassie, Emre, \& Çetin Gevrek, 2017). Sleep and circadian 
rhythms in critically ill patients are reported to be severely disrupted by many stimuli, for example, lack of deep sleep and rapid eye movement sleep (REM), and abnormal daily distribution of abnormal daily sleep-wake periods (Ding et al., 2017), (Pieris et al., 2018) (Ding et al., 2017; Topçu, Ecevit Alpar, Gülseven, \& Kebapçı, 2017; Naik et al., 2018) Achieving good sleep quality is very significant for health. Patients who are sick need more sleep and rest. Some organ systems function is affected by sleep quality. Thus sleep disorder would bring several consequences such as extended length of stay in the ICU and increase mortality (L.J., F., \& V., 2015), (Kaplow, 2016). The study conducted by Y, Boyko. et al., (2018) mentioned that the presence of atypical sleep patterns by the classification of sleep scores was associated with a higher chance of dying in the ICU. Previous studies had focused more on noise factors and had not examined the level of humidity and room temperature associated with sleep quality status in the ICU. The significance of this research is to find out the standard temperature, humidity, and the noise of the room as well as their relation to the quality of sleep of the patients.

\section{METHODS}

This was a quantitative research with a cross-sectional approach, involving 84 patients taken by consecutive sampling and with the inclusion criteria of at least having already spent more than two days in ICU, having age between 20-70 years, and bring conscious and cooperative. The instruments of the research used were observation sheets containing the demographic list, clinical data, treatment, level of consciousness, oxygen, protocol of temperature, humidity, and noise measurement, as well as monitoring sheet (day, time, vital sign, temperature (C), humidity (\%), noise (dB)) and the RichardsCampbell Sleep Questionnaire (RCSQ). The independent variable of this research was the quality of sleep of the patients, and the dependent variables are temperature, humidity, and noise. The sleep quality was measured by RCSQ, which includes 5 item questions of the depth of sleep, the latency of sleep, awakening time, time of going back to sleep, and sleep quality. This questionnaire used an analog visual scale with a score range of 1-100 (poor to excellent quality). The validity and reliability tests were not done as the questionnaire has been tested in several countries with the content and face validity of the questionnaire inter-rater correlation coefficient and the Cronbach's alpha value of 0.714 ( $\mathrm{p}<0.0001$ ) and 0.906 (Amirifar, Rahimi, Feizi, \& Sirati nir, 2018), respectively and has been used by a number of a researcher in Indonesia (Afianti \& Mardhiyah, 2017), (Mutarobin, Nurachmah, Adam, Sekarsari, \& Erwin, 2019).

After a back translation, the face validity test of the questionnaire was done with ten patients and proven understandable. The data of temperature and humidity were obtained using thermohygrometer. Moreover, a calibrated sound level meter was used to obtain the data of noise. Both instruments were digital tools with their ease in use. The first procedure of operating the instruments was to turn on the power button until numbers appeared on the screen. The average point of the temperature, humidity, and noise would be shown on the screen. To maintain the existing screen view in order to record the point shown on the screen, the hold button needed to be pressed. The instrument would record the temperature, humidity, and the noise of the room area closest to the patient.

After obtaining the research permit and qualifying for ethics, researchers began taking data by measuring temperature, humidity, and noise at night and during the day in the ICU room 1-2 days when patients were treated. In the morning, the researcher met the respondents who agreed to get an explanation about the aims and benefits of the study. They were then asked to sign an informed consent when the patients were not able to sign the consent. Their family member signed it on 
behalf of the patient. The researcher read and helped write the patient's answers on the questionnaire sheet, continued with the completeness of the questionnaire, and documented the data of the patients' treatments. Simple linear regression was used to analyze the data. This study was conducted in the ICU of Prof. dr. Margono Soekarjo hospital, Purwokerto, between July and September 2019. A research ethics permit was obtained from Prof. Dr. Margono Soekarjo hospital Purwokerto (No: 420 / 10144b/ VII / 2019).

Table 1. Characteristics of respondents based on sex, age, sleeping position, oxygen use, and surgery $(n=84)$

\begin{tabular}{lcc}
\hline Variable & n & \% \\
\hline Sex & 17 & 20.3 \\
$\quad$ Male & 67 & 79.8 \\
$\quad$ Female & & \\
Ages & 45 & 53.6 \\
$\quad$ < 40 year & 39 & 46.4 \\
$\quad \geq 40$ year & & \\
Length of stay & 50 & 59.5 \\
$\quad$ Two day & 30 & 35.7 \\
Three day & 4 & 4.8 \\
Four day & & \\
Sleep position & 28 & 34.2 \\
$\quad$ Supine & 15 & 17.9 \\
Fowler & 41 & 48.9 \\
Semi fowler & & \\
Oxygen & 77 & 91.7 \\
$\quad$ Nasal cannula & 1 & 1.2 \\
Non-Rebreathing Mask & 5 & 6.0 \\
Simple Mask & 1 & 1.2 \\
Rebreathing Mask & & 59.5 \\
Surgery & 50 & 40.5 \\
$\quad$ Yes & 34 & \\
No & & \\
\hline
\end{tabular}

Table 2. Mean score QOS, humidity, temperature and room noise

\begin{tabular}{lllc}
\hline Variable & Mean & SD & Min-Max \\
\hline QOS & 28.51 & 10.94 & $10-64$ \\
Humidity & 56.98 & 9.355 & $38-77$ \\
Temperature & 26.40 & 1.262 & $23-28$ \\
Noise & 66.01 & 6.202 & $54-88$ \\
\hline
\end{tabular}

Based on the results of this research, it 28.51, which meant most respondents had poor

was obtained an average score of QOS of

\section{RESULTS}

The result shows (table 1), most respondents in the study were female $(79.8 \%)$, age over 40 years old $(53.6 \%)$, had stayed in the ICU for two days (50\%). Approximately half of the respondents (48.9\%) slept in semi fowler position, and two-third of the patients were postoperative $(59.5 \%)$. The result of this study shows that the average sleep quality of patients in the intensive room was 28.51, which considered poor sleep quality. sleep quality. The result also showed that the 
average score of humidity was 56.98 , the room temperature was higher than the standard one, and the noise of 66.01 exceeded the standard of the Ministry of Health of Republic of Indonesia (Table 2).

Table 3 .Analysis of the effect of temperature, humidity, and noise on QoS

\begin{tabular}{lcrr}
\hline Variable & $\mathbf{B}$ & $\mathbf{9 5 \%} \mathbf{C I}$ & Sig \\
\hline Temperature & 0.237 & $2.504-2.029$ & 0.835 \\
Humidity & 0.114 & $0.153-0.345$ & 0.455 \\
Noise & 0.447 & $0.072-0.822$ & 0.020 \\
\hline
\end{tabular}

Logistic regression analysis was used to determine the effect of temperature, humidity, and noise on the quality of sleep of patients in the ICU. The results of the analysis (table 3) noted that among the three variables tested in the logistic analysis, only the significantly influential noise variable $(\mathrm{p}=0.020(<0.05)$ towards the patient's sleep quality (Table 3 ).

\section{DISCUSSIONS}

The average room humidity was $56.98 \%$, with a minimum value of 38 and a maximum of $77 \%$. This result is quite different from some previous studies which reported that the average humidity in the ICU was 29.95$36.13 \%$ (Şimşek et al., 2017) This result is higher than the (Indonesia, 2019) standard, which is in the range of $40-60 \%$. Relatively high humidity at room temperature above the thermo-neutral zone has an adverse effect on sleep. Humidity affects the rate of heat transferred by influencing evaporation so that the temperature dynamics are disturbed. The effect can be seen in scores of sleep quality, body temperature, and ambient temperature. Moisture can affect sleep through the homeostatic pathway, which may interfere with the accumulation of adenosine in the forebrain and affect the central sleep regulation and non-rapid eye movement (NREM). This condition can also affect circadian rhythms with a thermo-regulatory feedback disturbance mechanism that can affect the input of temperature changes to sleep settings (Manzar, Sethi, \& Hussain, 2012).
The results showed room humidity had no effect on patients' sleep quality ( $\mathrm{p}=0.455$ (> 0.05 ). These results are consistent with (L.J. et al., 2015) that increases in temperature and humidity can occur at night. Still, there are no reports of patient temperatures and humidity disturbing patients' sleep. Base on the result, the average temperature in the ICU was $26.4^{\circ}$ C. This result far exceeds the minimum standard (Indonesia, 2019), which is $22-23^{\circ} \mathrm{C}$. The temperature that is too cold and hot can affect sleep disorders of patients in the ICU (Norton, et al, 2015). This study found that the lowest temperature in the ICU was $23^{\circ} \mathrm{C}$ and the hottest was $28^{\circ} \mathrm{C}$. This finding certainly should raise awareness among health care professionals. There has to be a certain temperature regulation for patient comfort and patient safety. Furthermore, this study result showed that room temperature did not affect sleep quality ( $\mathrm{p}$-value of 0.455 (> 0.05). The results of this study are in line with research (Delaney, Currie, Huang, Lopez, \& Van Haren, 2018), which states that environmental factors (room temperature) are not significantly related to patient sleep quality.

Noise in this research means all sounds in the ICU room, and it was measured using a sound level meter. The average noise measurement result was 66.01 decibels (dBA). The minimum standard of noise in the ICU is, while the noise in the room must not exceed 65 decibels (dBA). The average noise level in this study was $66.01 \mathrm{dBA}$. The lowest sound level recorded was 54 decibels (dBA), whereas the maximum level was $88 \mathrm{dBA}$. This is of co, which, of course, exceeds the maximum limit of (Indonesia, 2019). The results of this study 
are in line with a previous study that found no relationship between noises and sleeps quality of patients. Noise in the ICU was found to exceed the normal standard. At noon, the noise in the ICU was around 60 decibels (dBA), it could reach its peak level until $90 \mathrm{dBA}$, while at night time the sound level plunged to approximately $50 \mathrm{dBA}$ (He et al., 2018). These results are far from the WHO standard for noises in the ICU. WHO stated that 35-40 $\mathrm{dBA}$ is the standard level during the day time and 30-40 dBA at night (Tainter et al., 2016). Based on the three variables tested in the logistic analysis, only the noise variable that significantly affected $(p=0.020(<0.05)$ the patients' sleep quality. The results of this study support (He et al., 2018)and (Crawford, Barnes, Peters, Falk, \& Gehlbach, 2018).The baseline data showed the noise level was between $54 \mathrm{dBA}$ and $88 \mathrm{dBA}$. These data were collected at night (23.00-02.00).

Furthermore, other previous studies (Delaney et al., 2018; Ding et al., 2017) reported that there is a relationship between noise and poor sleep quality. Moreover, Delaney et al., (2018) found that clinical care affected patients' sleep (34.3\%), while environmental noise made $32.1 \%$ disturbance towards patients' sleep quality. Patients reported that they found it very difficult to stay sleep in the hospital. The proportion of patients who reported poor sleep quality was 41.6, 34.2, and $24.2 \%$. Patients reported worse sleep quality than nurses $(\mathrm{p}<0.05)$. Sources of noise that can contribute to sleep disorders of patients treated in the ICU include alarms from infusion pumps, monitoring devices, ventilators, and normal ventilator functions, telephones, bedside conversations of patients (L.J. et al., 2015)(Pulak \& Jensen, 2016)(Drouot \& Quentin, 2016). However, AC sound does not have a significant positive effect on sleep duration, latency, and efficiency (Alkahtani et al., 2019). WHO (Crawford et al., 2018) recommends that the maximum level does not exceed $40 \mathrm{dBA}$ at night. The sound threshold that causes sleep disturbance is $63 \mathrm{dBA}$ during the day and 59
$\mathrm{dBA}$ at night. The most disturbing sources of noise were the alarm monitor (OR 4.5, 95\% CI 3.5-5.6) and ventilator alarm (OR 4.2, 95\% CI 2.9-6.1) (Elbaz et al., 2017).

The noise level in the ICU is negatively related to the restoration period and gender (K.S. et al., 2018). This noise can disrupt sleep, cardiovascular illness, and psychophysiological distress. Moreover, noises in the ICU would reduce performance, trigger disruption responses, and changes in social behavior (Basner et al., 2014). Alarm sounds, staff conversations, and noise that come from daily activities seem to disturb sleep the most. However, Hinton, (2016) argued whether noise in the ICU is a significant contributor to sleep disturbance. In addition to the direct effects of noise during sleep, unexpected sounds from sources outside the patient's control, such as alarms, can also improve sympathetic function and negatively affect heart function (K.S. et al., 2018).

Sleep disorders in the ICU are multifactorial. In addition to the previously identified environmental factors, a number of non-environmental factors, such as previous sleep quality at home, the use of regular sleeping pills before entering ICU, treatment for hypo and hyperthyroidism, plus the use of benzodiazepines and steroid administration during ICU stay in association with sleep quality reported bad. Although environmental factors such as telephone noise are important contributors to sleep disturbance in the ICU, other important factors were also detected (Bihari et al., 2012). In this study, almost all patients were given steroid and pain medication (ketorolac, tramadol, and other drugs) because pain medication was not part of the exclusion criteria in this research. Corticosteroids have been known to reduce REM sleep and slow-wave sleep and increase stage 2 awake and NREM sleep. Sleep disturbances in the ICU would contribute to patients' brain dysfunction in which the manifestation was delirium (Ding et al., 2017). Sleep disorders also occur among patients who are installed non-invasive ventilation (Pulak \& 
Jensen, 2016) because noninvasive ventilation could cause circadian rhythm disturbances and decreased REM sleep. The effect of sleep deprivation on a patient's physiological processes is a change in the patient's body temperature and circadian body rhythm which results in a decrease in temperature sensitivity during NREM sleep, whereas REM sleep is associated with loss of ability to shiver or sweat (Pulak \& Jensen, 2016).

Changes in breathing would lead to hypoxia and hypercapnia and contribute to ischemia and dysrhythmia in patients with a history of heart disease. Increased gastric acid secretion in the endocrine system causes hormonal instability, hallucinations, and distortion of perception. These conditions are considered to have an association with sleep deprivation in the ICU and also contribute to the development of delirium (Drouot \& Quentin, 2016), (Kaplow, 2016). Furthermore, some literature mentioned that the impact of disturbed sleep in the intensive room could cause negative physiological problems in the cognitive, autonomic, metabolic and hormonal systems in the body which can contribute to the length of the day of care and in turn can contribute to the increase in patient morbidity (K.S. et al., 2018).

In order to reduce noise in the intensive room, health care professionals should consider these 3 noise sources; conversations and staff activities, noise from medical devices, and noise from alarms. This is done by adapting conversations and staff activities, earplugs, and modifying alarms to improve sleep quality (K.S. et al., 2018). The limitation of this study is that researchers still made patients who received corticosteroid drugs become respondents, leaving almost all respondents using these drugs, which could have influenced the results of the study. Measurement of new sleep quality is measured using a questionnaire and has not yet used a polysomnographic measurement tool that can describe in detail sleep disturbance. Further research needs to be done to find out other factors that influence sleep quality from patient and environmental factors by minimizing research bias variables such as disease, therapy, and type of surgery and applying a measurement tool to the patient's sleep activity (polysomnography).

\section{CONCLUSIONS}

Most of the respondents had a poor quality of sleep. A correlation exists between the noise and the quality of sleep of the patients, but not between the humidity as well as temperature and the quality of the sleep of the patients. The noise at the ICU room must be reduced in accordance with the standard $\mathrm{dB}$. Therefore, every ICU room must have the sound level meter and thermogygrometer to ensure a good condition of the ICU room. Controlling the conversation and activities among staff, using earplugs, and modifying the alarm can be done to reduce the noise at the ICU in order to enhance the quality of sleep of the patients.

\section{ACKNOWLEDGEMENT}

Sincere gratitude was delivered to all survey respondents, staff, nurses and physicians of Prof. Dr. Margono Sokerjo hospital in Purwokerto, who were willing to contribute to this research also the Asoisasi Institusi Pendidikan Nasional Indonesia (AIPNI)-AINEC as a major funder as well as.

\section{REFERENCES}

Afianti, N., \& Mardhiyah, A. (2017). Pengaruh Foot Massage terhadap Kualitas Tidur Pasien di Ruang ICU. Jurnal Keperawatan Padjadjaran. https://doi.org/10.24198/jkp.v5n1.10

Alkahtani, M., Alshathri, N., Aldraiweesh, N., Aljurf, L., Aldaej, L., Olaish, A., ... BaHammam, A. (2019). The effect of air conditioner sound on sleep latency, duration, and efficiency in young adults. Annals of Thoracic Medicine. https://doi.org/10.4103/atm.atm_195_18

Amirifar, A., Rahimi, A., Feizi, F., \& Sirati 
nir, M. (2018). The Psychometric Properties of Richard Campbell Sleep Questionnaire in Patients in Intensive Care Unit. Critical Care Nursing. https://doi.org/10.5812/ccn.65483

Basner, M., Babisch, W., Davis, A., Brink, M., Clark, C., Janssen, S., \& Stansfeld, S. (2014). Auditory and non-auditory effects of noise on health. The Lancet. https://doi.org/10.1016/S01406736(13)61613-X

Bihari, S., Doug McEvoy, R., Matheson, E., Kim, S., Woodman, R. J., \& Bersten, A. D. (2012). Factors affecting sleep quality of patients in intensive care unit. Journal of Clinical Sleep Medicine. https://doi.org/10.5664/jcsm.1920

Carrera-Hernández, L., Aizpitarte-Pejenaute, E., Zugazagoitia-Ciarrusta, N., \& GoñiViguria, R. (2018). Patients' perceptions of sleep in a Critical Care Unit. Enfermeria Intensiva. https://doi.org/10.1016/j.enfi.2018.01.00 2

Crawford, K. J., Barnes, L. A., Peters, T. M., Falk, J., \& Gehlbach, B. K. (2018). Identifying determinants of noise in a medical intensive care unit. Journal of Occupational and Environmental Hygiene.

https://doi.org/10.1080/15459624.2018.1 515491

Delaney, L. J., Currie, M. J., Huang, H. C. C., Lopez, V., \& Van Haren, F. (2018). They can rest at home: An observational study of patients quality of sleep in an Australian hospital. BMC Health Services Research. https://doi.org/10.1186/s12913-0183201-z

Ding, Q., Redeker, N. S., Pisani, M. A., Yaggi, H. K., \& Knauert, M. P. (2017). Factors influencing patients' sleep in the intensive care unit: Perceptions of patients and clinical staff. American Journal of Critical Care. https://doi.org/10.4037/ajcc2017333

Dolan, R., Huh, J., Tiwari, N., Sproat, T., \&
Camilleri-Brennan, J. (2016). A prospective analysis of sleep deprivation and disturbance in surgical patients. Annals of Medicine and Surgery. https://doi.org/10.1016/j.amsu.2015.12.0 46

Drouot, X., \& Quentin, S. (2016). Sleep Neurobiology and Critical Care Illness. Sleep Medicine Clinics. https://doi.org/10.1016/j.jsmc.2015.10.00 1

Elbaz, M., Léger, D., Sauvet, F., Champigneulle, B., Rio, S., Strauss, M., ... Mira, J. P. (2017). Sound level intensity severely disrupts sleep in ventilated ICU patients throughout a $24-\mathrm{h}$ period: a preliminary 24-h study of sleep stages and associated sound levels. Annals of Intensive Care. https://doi.org/10.1186/s13613-0170248-7

Hadi. (2017). Factors affecting sleep disorders of patients in the intensive care unit. ICASH.

He, J., Li, H., Chen, X., Jin, S., Chen, M., Shi, L., \& Su, F. (2018). Noise Levels in a Medical Intensive Care Unit. (July). https://doi.org/10.20944/preprints201807 $.0588 . v 1$

Hinton, L. (2016). The intensive care unit was so noisy I couldn't sleep. BMJ (Online). https://doi.org/10.1136/bmj.i2150

Indonesia, K. K. R. (2019). Peraturan Menteri Kesehatan no 7 tahun 2019 tentang Kesehatan Lingkungan Rumah Sakit. In Jakarta, 19 februari 2019.

K.S., S., E., V., P.M.C., L., S., J., M., P., P.E., S., ... de Jager, C. P. C. (2018). Noise in the intensive care unit and its influence on sleep quality: A multicenter observational study in Dutch intensive care units. Critical Care. https://doi.org/10.1186/s13054-018-
2182-y LK
http://mgetit.lib.umich.edu/sfx_locater?si $\mathrm{d}=$ EMBASE\&issn=1466609X\&id=doi: 1 0.1186\%2Fs13054-018-2182

Kaplow, R. (2016). Sleep Disturbances and 
The Correlation Between Humidity, Temperature, and Noise with ... (Sri, et.al)

Critical Illness. Critical Care Nursing Clinics of North America. https://doi.org/10.1016/j.cnc.2016.02.005

L.J., D., F., V. H., \& V., L. (2015). Sleeping on a problem: the impact of sleep disturbance on intensive care patients - a clinical review. Annals of Intensive Care. https://doi.org/10.1186/s13613-015-

0043-2 LK http://sfx.library.uu.nl/utrecht?sid=EMB ASE\&issn $=21105820 \&$ id $=$ doi: $10.1186 \%$ 2Fs13613-015-0043-

Manzar, M. D., Sethi, M., \& Hussain, M. E. (2012). Humidity and sleep: A review on thermal aspect. Biological Rhythm Research.

https://doi.org/10.1080/09291016.2011.5 97621

Mutarobin, M., Nurachmah, E., Adam, M., Sekarsari, R., \& Erwin, E. (2019). PENERAPAN EVIDENCE-BASED NURSING PENGARUH EARPLUG DAN EYE MASK TERHADAP KUALITAS TIDUR PADA PASIEN DI ICU. Jurnal Keperawatan Indonesia. https://doi.org/10.7454/jki.v22i2.735

Naik, R. D., Gupta, K., Soneja, M., Elavarasi, A., Sreenivas, V., \& Sinha, S. (2018). Sleep quality and quantity in intensive care unit patients: A cross-sectional study. Indian Journal of Critical Care Medicine.

https://doi.org/10.4103/ijccm.IJCCM_65 _18

Pieris, L., Sigera, P. C., De Silva, A. P., Munasinghe, S., Rashan, A., Athapattu, P. L., ... Haniffa, R. (2018). Experiences of ICU survivors in a low middle income country-A multicenter study. $B M C$ Anesthesiology.

https://doi.org/10.1186/s12871-018-

0494-8

Pulak, L. M., \& Jensen, L. (2016). Sleep in the Intensive Care Unit: A Review. Journal of Intensive Care Medicine. https://doi.org/10.1177/08850666145387 49

R., S., B., R., \& K., R. (2014). Sleep disturbance in older ICU patients. Clinical Interventions in Aging.

Rahmawan, E. (2013). Hubungan Stres Psikologi Dan Obat-Obatan Dengan Kualitas Tidur Pada Pasien Kritis di Ruang Rawat Intensif di RSUD Tugurejo Semarang. Journal of Chemical Information and Modeling. https://doi.org/10.1017/CBO9781107415 324.004

Şimşek, E. M., Solak Grassie, S., Emre, C., \& Çetin Gevrek, S. (2017). Relationship between Environmental Conditions and Nosocomial Infection Rates in Intensive Care Unit. Medical Journal of Islamic World Academy of Sciences. https://doi.org/10.5505/ias.2017.66742

Tainter, C. R., Levine, A. R., Quraishi, S. A., Butterly, A. D., Stahl, D. L., Eikermann, M., ... Lee, J. (2016). Noise levels in surgical icus are consistently above recommended standards. Critical Care Medicine.

https://doi.org/10.1097/CCM.000000000 0001378

Tembo, A. C., Parker, V., \& Higgins, I. (2013). The experience of sleep deprivation in intensive care patients: Findings from a larger hermeneutic phenomenological study. Intensive and Critical Care Nursing. https://doi.org/10.1016/j.iccn.2013.05.00 3

Topçu, S., Ecevit Alpar, Ş., Gülseven, B., \& Kebapçı, A. (2017). Patient experiences in intensive care units: a systematic review. Patient Experience Journal. https://doi.org/10.35680/2372-0247.1137

Wilcox, M. E., Lim, A. S., Pinto, R., Black, S. E., McAndrews, M. P., \& Rubenfeld, G. D. (2018). Sleep on the ward in intensive care unit survivors: a case series of polysomnography. Internal Medicine Journal. https://doi.org/10.1111/imj.13791

Y., B., P., T., H., O., J.T., L., M., N., \& P.J., J. (2018). Sleep in critically ill patients and outcome.

Critical

Care. 
Jurnal INJEC Vol. 5 No. 1 June 2020: 60-68

https://doi.org/10.1186/s13054-018-

1973-5 